\title{
INDICADORES BIBLIOMÉTRICOS DA PRODUÇÃO ACADÊMICA INTERNACIONAL SOBRE O INTÉRPRETE EDUCACIONAL DE LÍNGUAS DE SINAIS
}

\author{
Neiva de Aquino Albres ${ }^{1}$ \\ Mairla Pereira Pires Costa 1 \\ 1 Universidade Federal de Santa Catarina, Florianópolis, Santa Catarina, Brasil
}

\begin{abstract}
Resumo: Este trabalho versa sobre a interpretação educacional de/para Língua de Sinais em diálogo com a Bibliometria. Partimos da premissa que a produção científica é uma rica fonte para compreender o desenvolvimento de determinada área e seus desdobramentos, e serve para mapear a dinâmica de dado objeto de investigação em inter-relação com os aspectos sociais, culturais e históricos. Fundamentada na perspectiva da arquitetônica bakhtiniana, que toma por base a organicidade discursiva dos textos (Bakhtin), esta pesquisa justifica-se pela complementaridade de estudos anteriores no Brasil (Albres e Lacerda; Gessner). Os objetivos são: i) revisitar esses trabalhos e ampliar o levantamento até 2020; ii) identificar as distribuições espaço-temporais, sintetizando os respectivos temas; e iii) mapear o desenvolvimento do campo da Interpretação Educacional de Línguas de Sinais (1990-2020) a partir desses textos. Para tal, selecionou-se cinco periódicos científicos internacionais sobre Educação de Surdos e sobre Linguística das Línguas de Sinais seguindo critérios pré-estabelecidos. Como resultados, identificou-se 38 artigos. Os temas que se destacam são: interpretação em sala de aula (53\%); inclusão escolar e formação de intérprete educacional (ambos 18\%). Concluímos que alguns temas foram pouco abordados, como saúde ocupacional, as competências para interpretar, os aspectos linguísticos e culturais relacionados à interpretação.
\end{abstract}

Palavras-chave: Pesquisa científica; Interpretação educacional em língua de sinais; Discursividade textual 


\title{
BIBLIOMETRIC INDICATORS OF INTERNATIONAL ACADEMIC PRODUCTION ON EDUCATIONAL INTERPRETATION OF SIGN LANGUAGES
}

\begin{abstract}
This research is about the educational interpretation of/for Sign Language in dialogue with Bibliometrics. We start from the premise that scientific production is a rich source for understanding the development of a certain area and its consequences, and it helps map the dynamics of a given object of investigation in interrelationship with social, cultural, and historical aspects. Furthermore, it follows the perspective of Bakhtin, which is based on the discursive organicity of texts (Bakhtin), this research is justified by the complementarity of previous studies in Brazil (Albres and Lacerda; Gessner). Therefore, the objectives are: i) to revisit these works and expand the survey until 2020, ii) to identify the Spatiotemporal distributions, summarizing the respective themes and; iii) to map the development of the Educational Interpretation of Sign Languages field (1990-2020) from these texts. Five international scientific journals on Deaf Education and on Sign Language Linguistics were selected, following pre-established criteria. As a result, 38 articles were identified and the themes are classroom interpretation (53\%); school inclusion, and educational interpreter training (both 18\%). Finally, we concluded that some themes were not addressed much, such as occupational health, skills to interpret, Linguistic and Cultural aspects related to interpretation.
\end{abstract}

Keywords: Scientific research; Educational Sign Language Interpretation; Textual discursivity

\section{Introdução}

As pesquisas sobre línguas de sinais e seus usos em diferentes esferas, como suas aplicações sociais, têm crescido consideravelmente (Santos; Santiago; Rodrigues). Estudos da Tradução e Interpretação de Línguas de Sinais (Etils) inscritos no campo dos Estudos da Tradução (ET) e no dos Estudos da Interpretação (EI) têm construído um legado para a compreensão do fenômeno da mediação linguístico-discursiva fundamentado em diferentes perspectivas teóricas, fazendo uso de distintas metodologias e abordando temas 
diversos (Albres, Afetividade e subjetividade). Sobre a vinculação direta dos Etils aos ET, Vasconcellos afirma que

[...] a inserção estratégica do tradutor e do intérprete de línguas de sinais em um campo disciplinar já estabelecido, longe de diminuir a importância de sua questão identitária, pode contribuir para o fortalecimento do empoderamento (empowerment) desses profissionais que, mesmo filiados a um campo disciplinar já constituído, não perdem sua especificidade ou visibilidade (Vasconcellos 121).

As línguas de sinais foram introduzidas nas pesquisas dos Estudos da Tradução (ET) e no dos Estudos da Interpretação (EI) bem recentemente. Quando do estabelecimento do campo disciplinar ET, o americano James S. Holmes (1972), em que no seu artigo "The name and the nature of translation studies" (O nome e a natureza dos estudos da tradução), aborda a necessidade de se consolidar a tradução como disciplina e apresenta um mapa conceitual em que classifica os temas que constituem os Estudos da Tradução (Pym 216), corroborando a importância do campo disciplinar e considerando os Estudos da Tradução como grande área, que nasce do encontro de pesquisadores e se consolida como uma disciplina acadêmica e "é por isso que a história é importante - esse paradigma particular não tem as mesmas origens que os outros", inclusive para compreender os deslocamentos das pesquisas da prescrição para a descrição de traduções e das diferentes correntes e temas de interesse.

Mais especificamente nos anos de 1990 tem início as pesquisas sobre interpretação de línguas de sinais (Metzger). Consideramos que os Estudos da Interpretação precedem os da Tradução, no que se refere às pesquisas envolvendo línguas de sinais, em virtude de sua materialidade ser a corporeidade e o escasso ou não popular uso de vídeo-gravação de 1990 a 2000, algo que tem mudado atualmente. Assim, tanto as práticas interpretativas quanto as situações de 
mediação entre surdos e ouvintes eram, em sua grande maioria, de interpretação entre línguas vocais-auditivas ${ }^{1}$ e línguas de sinais.

Dentre as esferas de atuação tradutória e interpretativa em alguns contextos de serviços públicos, as pesquisas no Brasil têm se concentrado nos contextos de educação, saúde e justiça (Rodrigues e Santos). Temos desenvolvido, portanto, pesquisas para compreender as práticas tradutórias e interpretativas em sala de aula, formação, discursos e concepções, como também condições de trabalho no contexto da Educação de surdos por tradutores e intérprete de Libras-português (Albres, Intérprete educacional; Estudos sobre os papéis; Afetividade e subjetividade, Políticas de contratação; Albres e Costa; Albres e Rodrigues).

No âmbito da pesquisa científica, conhecer os contextos de existência dos fenômenos construídos, assim como o que já foi produzido de conhecimento sobre a temática e seus desdobramentos, se faz essencial. Nesse sentido, propomos um estudo bibliométrico, delimitando artigos científicos internacionais escritos em língua inglesa a fim de contribuir para um mapeamento da área e servir como base para pesquisadores brasileiros que se interessem pela temática da interpretação educacional, ou como um banco de textos para revisão de literatura de outros estudos.

As questões que guiam este estudo são: Quais são as pesquisas publicadas entre os anos de 1990 e 2020 sobre interpretação educacional em periódicos internacionais de, entre ou para língua de sinais? Quais os temas abordados e suas contribuições para a

\footnotetext{
${ }^{1}$ As línguas vocais-auditivas são conhecidas como as línguas criadas e usadas por pessoas ouvintes, chamadas como línguas orais-auditivas, com enfoque para a forma de produção pela emissão de sons e de recepção da língua pela audição, geralmente, são classificadas em oral-auditivas e gestuais-visuais. Alguns autores têm optado por denominá-las de língua de modalidade vocal-auditiva (oral) versus línguas de modalidade gestual-visual, que seriam as línguas de sinais (Rodrigues, 2013). Para Leite (2019), todo o corpo é base da oralidade, independente da condição do falante (surdo ou ouvinte) e da predominância da língua, para tanto propõe chamarmos as línguas de sinais de língua (corp)oral, centrada nos articuladores manuais em comparação às línguas sonoras que se centram nos articuladores vocais.
}

Cad. Trad., Florianópolis, v. 41, n$^{0}$ esp. 2, p. 68-106, ago/dez, 2021. 
compreensão da atividade de interpretação educacional na educação de surdos?

Nosso objetivo, portanto, é apresentar um desenho das pesquisas sobre a interpretação educacional de/para língua de sinais compreendendo trinta anos (1990 a 2020), contextualizado com as mudanças relacionadas à reestruturação dos programas de pós-graduação e instituições internacionais, inseridos em políticas públicas globais de inclusão escolar, nas políticas educacionais e nas políticas linguístico-tradutórias, como também no desenvolvimento da tecnologia com seus desdobramentos nas condições da produção do conhecimento científico.

\section{Produção de pesquisas em Ciências Humanas}

Historicamente, a filosofia é tomada como princípio do fazer científico, logo, com a incidência da perspectiva positivista de rigor metodológico se sobrepõe às questões subjetivas e de reflexão do pensamento puro, a perspectiva ideológica do pesquisador é desarrimada em prol da racionalidade neste domínio (Bakhtin, Notas sobre literatura). No processo do conhecimento, a tríade que se estabelece é "o sujeito que conhece, o objetivo do conhecimento e o conhecimento como produto do processo cognitivo" (Schaff 72).

Assim, o produto do processo cognitivo de um pesquisador pode ter diversos formatos. Dentre eles, o artigo científico tem ganhado espaço e grande valor no campo editorial, principalmente, por congregar os achados científicos de forma concisa e por sua fácil circulação acadêmica.

Inspiradas nas proposições de Bakhtin e do Círculo, compreendemos que o texto acadêmico, mais precisamente o artigo científico, tem uma organicidade do discurso específica, o que contribui significativamente para uma nova perspectiva a respeito do que se tem chamado, no campo científico, de revisão de literatura, que envolve toda uma normativa de citações e atribuição da autoria de 
conhecimento produzido anteriormente ao que cada pesquisador está estudando no momento.

É plausível afirmar que a arquitetônica bakhtiniana fornece elementos que contribuem para possíveis caminhos de estudar a linguagem e os discursos numa perspectiva dialógica. Baseadas em Bakhtin (Para uma filosofia do ato responsável), empregamos o termo 'arquitetônica' como um elemento estrutural-relacional concreto do ato, que se orienta na participação singular no existir humano. Nessa perspectiva, se relacionam a linguagem e a ideologia de seres concretos nos momentos arquitetônicos: eu-para-mim, outro-para-mim, e eu-para-o-outro, envoltos em valores que acontecem de forma específica no tempo e no espaço. Assim, para a análise de uma obra, seja ela literária ou técnico-científica, não se pode abstrair o seu contexto histórico e ideológico, logo, destaca-se a relação sujeito-objeto, ou seja, autor-discurso.

Queremos dizer que a escrita de artigos científicos como um objeto estético e ético assume um caráter particular que não pode ser dissociada do sujeito que a produz (autor-criador) e das condições materiais e históricas para sua execução. Dessa forma, compreendemos que cada texto é singular, único. Portanto,

a forma de auto-suficiência, de auto-satisfação, inerente a tudo o que é esteticamente acabado, é uma forma puramente arquitetônica e impossível de ser transferida para a obra como material organizado, pois esta apresenta-se como uma entidade teleológica composicional onde cada momento e todo o conjunto estão voltados para um fim, realizam algo, servem para algo (Bakhtin, Para uma filosofia do ato responsável 24).

Do modo como exemplifica Bakhtin (Para uma filosofia do ato responsável), ao tratar das formas arquitetônicas, os gêneros do discurso organizam-se em formas composicionais, relacionadas às escolhas verbais que se materializam num acontecimento his- 
tórico e social. Cada forma arquitetônica "é realizada por meio de métodos composicionais definidos; por outro lado, às formas composicionais mais importantes, às do gênero, por exemplo, correspondem, no objeto realizado, formas arquitetônicas essenciais" (Bakhtin 24). A forma arquitetônica nos permite sempre perguntar quem produziu, para quem e em que circunstâncias (Sobral).

Assim, a análise da produção científica sobre uma temática específica, como tentamos delimitar para este artigo, voltando-nos para a atividade de interpretação educacional, segue os princípios apontados por Brait (cap. 1) para uma análise dialógica da linguagem. Debruçar-se sobre um corpus de artigos científicos inclui perceber que cada texto compõe práticas discursivas, ou seja, são enunciações concretas, ao mesmo tempo que compõem contextos mais amplos de produção e circulação dos discursos.

\section{Aspectos teórico-metodológicos}

A metodologia adotada no presente trabalho foi o estudo bibliométrico, que consiste em um conjunto de princípios que contribuem para o estabelecimento teórico do campo de uma ciência em questão. A função do estudo bibliométrico é a gestão do conhecimento socialmente construído. Segundo Pritchard (qtd. in Beuren and Souza 3), estudos bibliométricos são "todos os estudos que tentam quantificar os processos de comunicação escrita”, o que permite estabelecer perfis dos estudos de determinada área.

Ao fazer uso desse método, é possível identificar trabalhos, teorias e autores que estão sendo utilizados para o desenvolvimento do capital científico da área estudada e seu desenvolvimento cronológico, podendo identificar o crescimento ou não da área pesquisada (Vanti 369-379). 


\section{Delimitação do Corpus}

Foram selecionadas cinco revistas acadêmicas publicadas em língua inglesa, que tivessem como objetivo a divulgação de trabalhos sobre língua de sinais, educação de surdos, interpretação em língua de sinais e que fossem disponibilizadas online, mesmo que apenas o resumo. Selecionamos estas cinco revistas por representarem maior impacto acadêmico e reconhecimento na comunidade surda, por serem produzidas por instituições renomadas como a Gallaudet University nos Estados Unidos e a Oxford Academy na Inglaterra. Por sua vez, a revista International Journal of Interpreter Education foi criada a partir da "Conference of Interpreter Trainers (CIT)", fundada em 1979 com o objetivo de capacitar a troca de informações entre formadores de intérpretes de língua de sinais nos Estados Unidos por meio de uma convenção bienal. A Gallaudet University Press estabeleceu a série de livros "Formação de Intérpretes", que publica alguns dos trabalhos apresentados no evento, dando maior credibilidade a essa revista ${ }^{2}$. A revista The Sign Language Translator And Interpreter, apesar de sua descontinuidade a partir de $2010^{3}$, a exclusividade temática inerente a interpretação educacional de/para língua de sinais é relevante para o escopo desta pesquisa. Segundo o site da revista, "o título continuará na forma de uma série de livros revisados por pares, que será chamada The Sign Language Translator and Interpreter Series" (Genamics JournalSeek) ${ }^{4}$

Em trabalhos anteriores, foram desenvolvidas análises das publicações por revista, identificadas por décadas/anos de publicação, autores e instituições vinculadas às pesquisas até o ano de 2010 (Albres e Lacerda) e, posteriormente, ampliada por Gessner, que

\footnotetext{
${ }^{2}$ Para maiores informações: http://gupress.gallaudet.edu/interpreter-educationseries.html.

${ }^{3}$ Mantém-se o acesso gratuito na versão eletrônica dos três primeiros volumes da revista, mediante solicitação.

${ }^{4}$ Disponível em: http://journalseek.net/cgi-bin/journalseek/journalsearch.cgi?fiel $\mathrm{d}=$ issn\&query $=1750-3981$.
} 
abarcou o período de 2010 a 2015. Nos propomos, nesse estudo, expandir a análise, abrangendo de 1990 a 2020, a fim de investigar os aspectos temáticos e metodológicos das pesquisas selecionadas.

Albres e Lacerda levantaram sete revistas, todavia, não encontraram publicações nas revistas Sign Language \& Linguistics $^{5}$ e na revista Deafness \& Education International ${ }^{6}$. Então, para este trabalho, optou-se por focar nas revistas do campo de Estudos Surdos, Educação e Tradução e Interpretação, como demonstrado na Figura 1, a seguir.

Figura 1 - Periódicos analizados

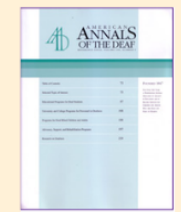

\section{American Annals} of the Deaf (AAD)

Publicada pela primeira vez em 1847, é a mais antiga revista acadêmica em inglês com a temática da surdez e da educação de surdos, coordenada pela Gallaudet University nos EUA. São mais de 150 anos de trabalho, mas apenas as edições a partir de 1991 estão digitalizadas e disponíveis no Portal de Periódicos da CAPES.

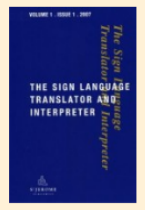

\section{The Sign Language Translator} and Interpreter (SLTI)

Com início em 2007, tendo apenas os três volumes publicados, foi interrompida em 2010. Esta decisão aconteceu pela constatação dos editores de haver poucos especialistas em tradução de língua de sinais vinculados aos espaços acadêmicos de pesquisa. Por este motivo não conseguiram manter um fluxo consistente de artigos de qualidade.

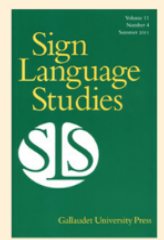

2. Sign Language Studies (SLS)

Coordenada pela Gallaudet University nos Estados Unidos da América, começou a ser publicad em 1972 e disponivel no Portal CAPES apenas a partir de 2000.

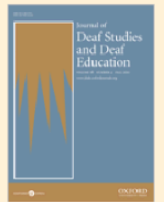

3. Journal of Deaf Studies and Deaf Education (JDSDE)

Vinculada à Oxford Academia na Inglaterra. A revista teve início em 1996 e as publicações estão acessíveis desde sua criação, contando com 13 volumes; disponibilizando os textos completos dos artigos.

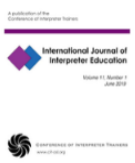

5. International Journal of Interpreter Education (IJIE)

Pioneira, abordando temas de interesse para pesquisadores que trabalham com a formação de intérpretes. Está vinculada à Fremont, California - Estados Unidos da América. Foi criada em 2009 e tem um volume publicado anualmente, no qual todos os artigos são focados no trabalho dos formadores de intérpretes.

Fonte: Produzido pelas autoras.

${ }^{5}$ Disponível em: http://www.jbe-platform.com/content/journals/1569996x.

${ }^{6}$ Disponível em: http://maney.co.uk/index.php/journals/dei/. 
Traçamos como objetivos para este artigo:

i. i) revisitar o trabalho de documentação de informações referentes à pesquisa em Estudos da Tradução e Interpretação de Línguas de Sinais, publicado por Albres e Lacerda e; Gessner e ampliar o levantamento até 2020 , dando continuidade ao estudo; e

ii. ii) identificar distribuições espaço-temporais dos artigos, bem como sintetizar os temas, traçando o desenvolvimento do campo de Interpretação Educacional.

\section{Procedimento de seleção e análise: a construção da pesquisa}

Nossa busca inicial se deu pelos títulos dos artigos e, em sequência, pelos resumos dos títulos selecionados que contemplassem as palavras: interpretação educacional (educational interpreting) e/ ou interpretação de língua de sinais (sign language interpreting). Num segundo momento, localizamos alguns artigos com temáticas relacionadas à inclusão escolar e/ou educação de surdos e que, apesar de não explicitar no resumo ou título a questão da interpretação, versavam sobre a interpretação educacional. Apesar de não termos trabalhado com descritores do campo da educação para busca, os descritores anteriores sobre interpretação indicaram também os textos de educação e inclusão educacional.

Tivemos acesso, inicialmente, ao abstract, parte indispensável do artigo científico exigida pelos periódicos acadêmicos. Alguns desses periódicos têm como diretriz o aceite de pesquisas em andamento, além das pesquisas concluídas. Para submissão do artigo, o abstract deve apresentar de forma sucinta todo o processo de pesquisa e seus resultados, mesmo que parciais.

Para este trabalho, acessamos o texto completo de todos os artigos por meio dos portais dos periódicos selecionados que, em sua maioria, são de acesso aberto, ou por meio de plataformas que hospedam publicações científicas. A principal plataforma que 
usamos foi o Projeto MUSE ${ }^{7}$, que fornece conteúdos nos campos das Ciências Humanas e Sociais, pagos e de acesso restrito para assinantes, contudo dispõe de publicações com acesso livre, que abre "novas perspectivas para a participação da ciência produzida [...], aumentando não apenas a visibilidade de seus periódicos" e da difusão do conhecimento científico (Borges 14). Disponibilizamse, principalmente, livros e artigos.

Os periódicos American Annals of the Deaf, Sign Language Studies, The Journal of Deaf Studies and Deaf Education não possuem acesso aberto às publicações, por isso, utilizamos o serviço de autenticação remota da Universidade Federal de Santa Catarina (UFSC) por meio do VPN (Virtual Private Network) ${ }^{8}$, no qual foi possível consultar as bases de dados internacionais e fazer o download dos textos, diferentemente dos periódicos The Sign Language Translator And Interpreter e International Journal Of Interpreter Education, em que o texto completo está acessível. Como mencionamos anteriormente, devido à falta de algumas informações nos resumos, como, por exemplo, os procedimentos metodológicos empregados pelos pesquisadores, foi fundamental acessar o artigo completo.

A fim de subsidiar a análise do corpus, elaboramos um quadro', listando os artigos por periódico e ordenados cronologicamente. Os dados informados foram: i) a referência bibliográfica (segundo a NBR 6023/2008 da Associação Brasileira de Normas Técnicas); ii) o título e o resumo traduzidos; iii) as palavras-chave (quando informado); iv) o tema (conforme classificação formulada pelas autores dessa pesquisa); v) o nível de ensino (quando informado no artigo); e vi) os principais resultados apresentados no texto.

\footnotetext{
${ }^{7}$ Acesso em: https://muse.jhu.edu/.

8 “Esse serviço é prestado para alunos, professores e técnicos da instituição na forma de autoserviço, ou seja, o próprio usuário é responsável pelo cadastro e pela configuração do serviço em seu computador" (UFSC). Disponível em: https:// setic.ufsc.br/servicos/acesso-a-redeufsc/servico-de-vpn-virtual-private-network/. ${ }^{9}$ As referências bibliográficas registradas no quadro foram listadas no apêndice.
} 


\section{Tradução/interpretação de língua de sinais na esfera educacional}

A área da Interpretação Educacional se configura como uma área específica, pois demanda questões e análises próprias, como formação do intérprete, familiarização com o conteúdo acadêmico onde trabalha, habilidades de interpretação apropriadas para cada tipo de público, entre outros aspectos (Marschark, Sapere and Seewagen).

No Gráfico $1^{10}$, apresentamos uma linha histórica com dados da criação e disponibilização das revistas científicas analisadas. A primeira revista (American Annals of the Deaf) é de 1847, foi publicada inicialmente na forma impressa e seu acervo online foi disponibilizado somente a partir do ano 1991, assim como a Sign Language Studies, criada em 1972, com textos em formato digital a partir de 2001. A revista Journal of Deaf and Deaf Education tem acesso aberto aos artigos, The Sign Language Translator and Interpreter foi encerrada em 2010 e International Journal of Interpreter Educacional foi criada exclusivamente em formato digital. Os artigos foram levantados a partir de 1990, considerando a delimitação de Albres e Lacerda, quando da disponibilização online no Portal de Periódicos da CAPES. Atualmente, é possível acessar textos antes desse período.

\footnotetext{
10 Adotamos, neste trabalho, uma comunicação visual para apresentação dos dados. Dessa forma, exploramos a construção de gráficos, diagramas, esquemas visuais com os dados numéricos em percentual ou de informações conceituais. De forma genérica, denominamos como "gráfico" e os numeramos em ordem cronológica, apesar de serem, em sua maioria, infográficos.
}

Cad. Trad., Florianópolis, v. 41, n$^{0}$ esp. 2, p. 68-106, ago/dez, 2021. 
Gráfico 1 - Linha histórica de publicação das revistas

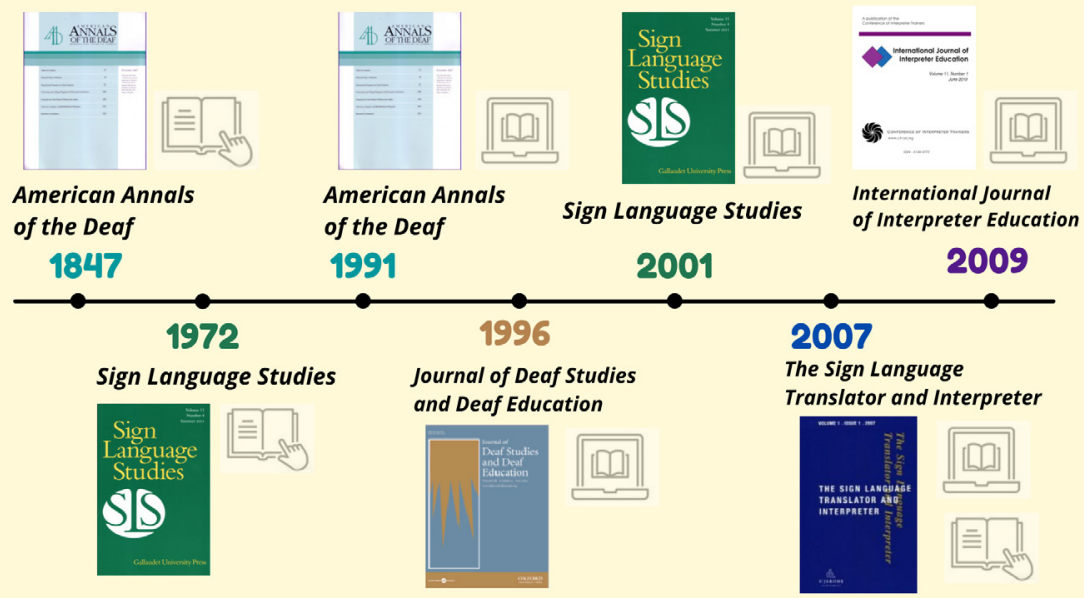

Fonte: Elaborado pelas autoras.

As publicações sobre tradução e/ou interpretação de língua de sinais na esfera educacional levantadas nas cinco revistas somaram um total 38 artigos (Gráfico 2). Constatamos uma diferença significativa no volume de publicações por periódico, conforme apresentado no gráfico: a revista American Annals of the Deaf (AAD) com 14 artigos, Sign Language Studies (SLS) com dois artigos, Journal of Deaf Studies and Deaf Education (JDSDE) com 14 artigos, The Sign Language Translator and Interpreter (SLTI) com apenas um artigo, e International Journal of Interpreter Education (IJIE) com sete artigos. 
Gráfico 2 - Número de artigos por revista
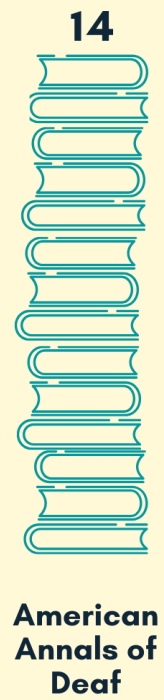
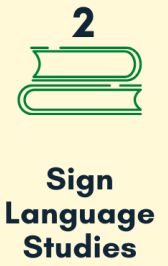

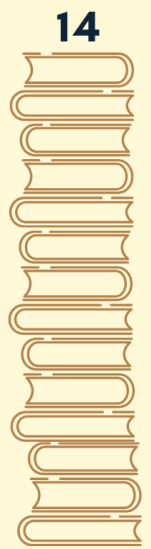

Journal of Deaf Studies and Deaf Education

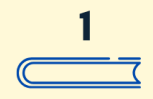

The Sign Language Translator and Interpreter

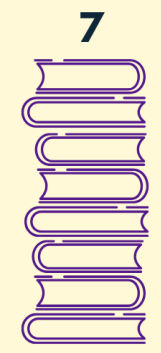

International Journal of Interpreter Education

Fonte: Produzido pelas autoras.

Identificamos outros artigos sobre interpretação educacional publicados pelo periódico American Annal of Deaf antes de 1990, como o artigo de Zawolkow e DeFiore (1986), intitulado Educational interpreting for elementary and secondary level hearing-impaired students, e o artigo An update on communication trends at programs for the deaf, de Jordan, Gustason, Rosen, publicado em 1979. Ambos trazem dados relevantes para o campo da Interpretação Educacional. Contudo, optamos por não os incluir no corpus. Assim, delimitamos a busca de 1990 a 2020, complementando o estudo de Albres e Lacerda e ampliando a busca manual nos sumários das revistas, principalmente, de 2015 a 2020.

Metzger indica que os primeiros estudos sobre interpretação de língua de sinais (ILS) começaram nos Estados Unidos nos anos 
1970 e somente nos anos de 1980 que se iniciam os estudos sobre interpretação de línguas de sinais em contextos educacionais. Averiguamos nestas revistas que apenas nos anos 1980 começam as publicações sobre interpretação nessa esfera. Albres e Lacerda (190) afirmam que, no Brasil, “as publicações sobre interpretação educacional se intensificam no período investigado (a partir dos anos 1990), podendo ser associada à discussão política mundial de inclusão educacional, entre outros fatores", coincidindo com os dados encontrados por nós.

Ao verificar os artigos por década, constatamos que nos anos 1990 foram publicados nove artigos, nos anos 2000 somamos 16 artigos e de 2010 a 2020 compilamos 13 artigos. Com isso, não se evidencia uma mudança significativa na quantidade de artigos por ano, ou mesmo por década. Dessa forma, mantém-se uma média de dois artigos por ano. Pode-se apresentar essa informação por revista e por década, como no Gráfico 3.

Gráfico 3 - Artigos publicados por revistas por década

REVISTA

American annals of the deaf

Sign Language Studies

Journal of Deaf Studies and Deaf Education

The Sign language translator and interpreter

International Journal of Interpreter Education
1990-1999

2000-2009

2010-2019

\begin{tabular}{|ccc|}
\hline 4 & 4 & 6 \\
\hline 1 & 1 & 0 \\
\hline 4 & 10 & 0 \\
\hline 0 & 1 & 0 \\
\hline 0 & 0 & 7 \\
\hline
\end{tabular}

Fonte: Produzido pelas autoras.

Os dados expostos no Gráfico 4 indicam o fluxo dos artigos específicos sobre interpretação educacional em cada periódico, por ano de publicação. O gráfico apresenta cinco linhas com cores e formatos distintos, nas quais os números expressam a quantidade de artigos que compõem o corpus analisado. Evidencia-se que o 
tema de interpretação educacional se consolidou e manteve um número constante com pesquisas articulando aspectos correlatos às situações e contextos de processos de ensino e aprendizagem e de instituições de ensino em que havia alunos surdos.

Gráfico 4 - Artigos publicados nas revistas analisadas por ano

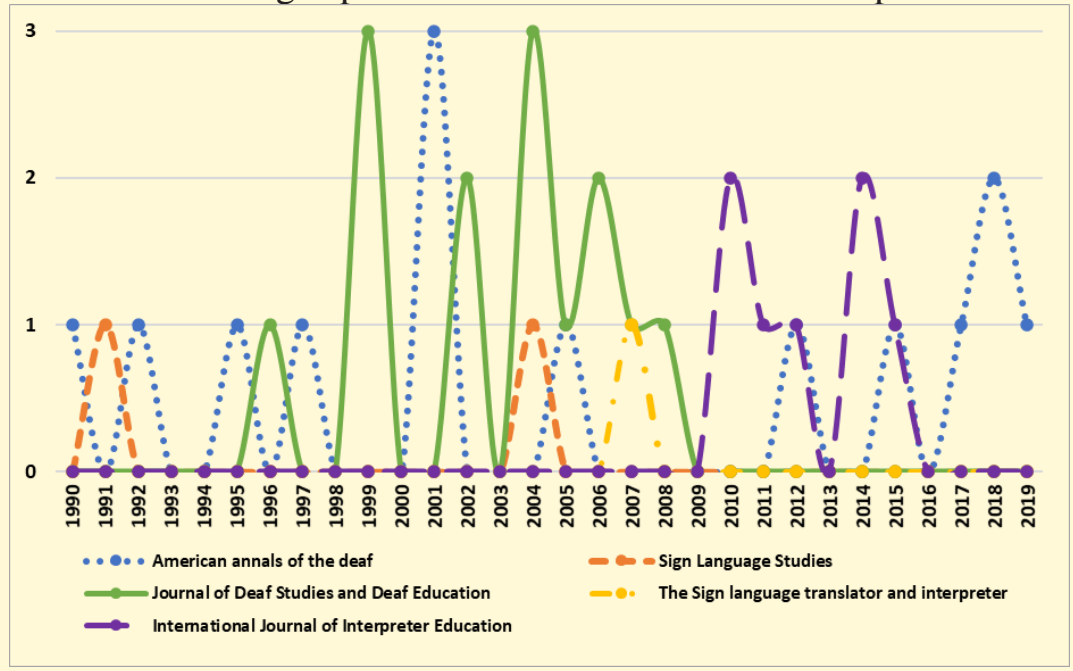

Fonte: Produzido pelas autoras.

O interesse em examinar esse dado não está alicerçado apenas na expressão numérica, se não da possibilidade de olhar a história desse campo de pesquisa tão rico, observar e narrar o desenvolvimento das discussões e problematizações sobre o tema, pois nessas pesquisas pulsam contextos singulares, experiências em instituições particulares articulados em tempos históricos e políticos específicos. Dessa forma, não nos cabe comparar as pesquisas, mas sim descrever e relatar as mudanças de interesses, as nuances de cada investigação e as escolhas dos pesquisadores.

Para esse estudo, pretendíamos analisar o nível de ensino, entretanto $35,89 \%$ das pesquisas, isto é, 14 artigos, não foram realizados necessariamente em espaços de sala de aula. Do mesmo 
modo, também cogitamos investigar as palavras-chave, porém identificamos que, dos 38 artigos, apenas 12 continham palavras-chave (três ou cinco palavras). As palavras utilizadas são bastante distintas, sendo que a maioria delas tem ocorrência única, por isso não viabilizou chegar a uma amostragem significativa para esse tipo de discussão.

As palavras-chave são elementos importantes nas estratégias de busca, além do título e do resumo. A depender dos recursos de pesquisa disponibilizados nos sites dos periódicos ou nas plataformas de acesso, há maior ou menor facilidade para localizar documentos. Optamos por acessar cada edição entre 2015 e 2020, porque percebemos que algumas publicações não explicitavam a interpretação ou o intérprete no resumo ou no título, mas mencionavam a atividade ou o profissional no decorrer da pesquisa.

A partir da leitura dos trabalhos, desenvolvemos uma classificação por tema principal do artigo. Cada trabalho tem sua especificidade e foco de interesse. Para agrupá-los de forma mais abrangente, seguimos os preceitos da categorização de James S. Holmes, a partir do modelo descritivo das áreas dos Estudos da Tradução.

Dessa forma, constatamos estudos aplicados que abordam o tema de formação de intérpretes (pesquisa-ação em formação continuada, seja em cursos, treinamento, revisão de currículos), como também estudos aplicados que problematizam as políticas de tradução envolvendo inclusão escolar e políticas públicas. Há também estudos aplicados configurando-se como uma crítica de tradução, ou seja, de avaliação da interpretação discutindo a fidelidade, estratégias interpretativas, etc. Verificamos alguns estudos descritivos orientados ao processo interpretativo em situações de interação em sala de aula e de mobilização dos discursos.

Apresenta-se, no Gráfico 5, as temáticas do corpus analisado. Destaca-se a interpretação em sala de aula (53\%) como tema mais recorrente, com 21 artigos, seguido pela inclusão escolar e formação de intérprete educacional (ambos 18\%) com sete artigos cada, e educação de surdos, competências interpretativas e segurança do trabalho, com um artigo para cada tema (3\%). 
Gráfico 5 - Temas dos artigos

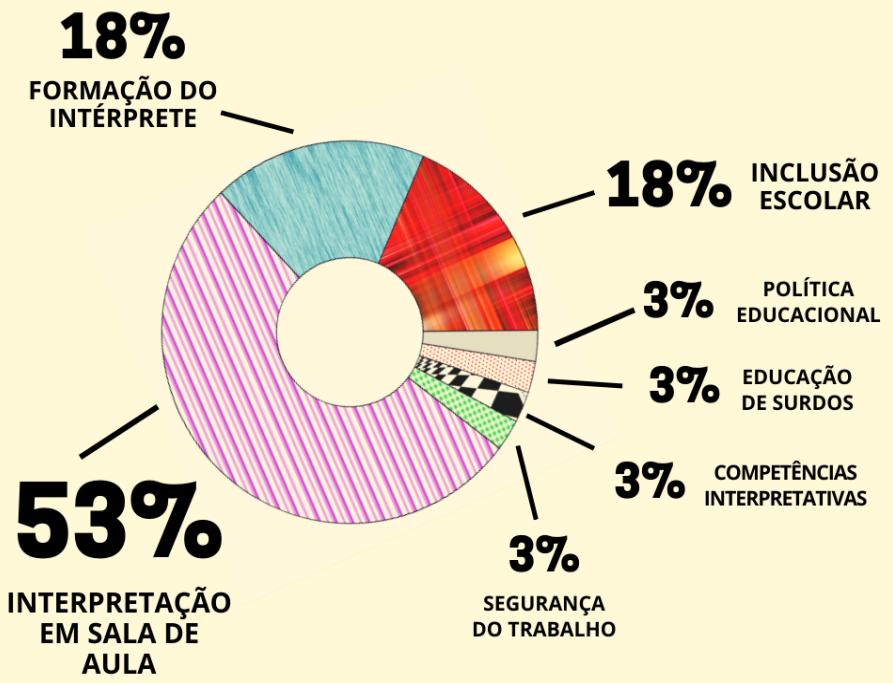

Fonte: Elaborado pelas autoras.

A fim de apresentar uma síntese das pesquisas, organizamos a exposição por tema, seguido pela revisão em ordem cronológica das publicações, procurando apreender a essência dos trabalhos, os propósitos e problematizações, do mesmo modo, discorrendo sobre as contribuições científicas dos estudos.

\section{Interpretação em sala de aula:}

As publicações sobre interpretação em sala de aula comportam o maior número, com 20 artigos (53\%). Compendiando os trabalhos, alguns artigos citam a tendência educacional desse período, que está direcionada à inclusão de alunos com deficiência. A investigação de Beaver, Hayes e Luetke-Stahlman situa-se nesse contexto. Professores do ensino fundamental e médio que trabalham com intérpretes 
educacionais e que, após participação em programa de treinamento, responderam perguntas sobre os serviços prestados por esses profissionais. O estudo constatou a importância desses programas que instruam o professor que trabalha com intérprete. Nessa mesma direção, Shaw e Jamieson verificaram o padrão discursivo entre professor, intérprete, aluno surdo e alunos ouvintes, analisando como transcorre a interação entre eles. Verificou-se que o aluno surdo interagia predominantemente com o intérprete, e que o discurso ao qual foi exposto era em grande parte acadêmico e não cultural ou social.

Identificamos quatro pesquisas que visavam avaliar a interpretação educacional. Schick, Willians e Bolster utilizaram o exame Educacional Interpreter Performance Assessment (EIPA), na qual a formação e atuação dos profissionais foi verificada. Os resultados mostraram que nem todos os intérpretes estavam qualificados para realizar uma interpretação adequada em sala de aula, e que as habilidades de vocabulário eram significativamente melhores do que as habilidades gramaticais. No âmbito do ensino superior, o estudo de Johnson visou analisar a interpretação em turma com alunos surdos e ouvintes, apontando a incompreensão e/ou falhas de comunicação nos momentos de explicação dos conteúdos e interação com os colegas ouvintes. Os dados ilustram mal-entendidos, quando os intérpretes não estavam familiarizados com o assunto ou quando interpretavam imagens ou discursos envolvendo descrições. Também foi relatada a dificuldade enfrentada pelo aluno surdo em olhar simultaneamente para o quadro e para o intérprete.

Schick, Williams e Kupermintz (2006) avaliaram 2.100 intérpretes educacionais nos Estados Unidos da América, também usaram o exame EIPA e constatam que as habilidades e conhecimentos do intérprete educacional são um aspecto crítico, mesmo os que tinham passado por programa de treinamento de intérpretes. Os autores afirmam que os alunos surdos recebem serviços de interpretação que irão dificultar seriamente o acesso ao currículo da sala de aula e à interação social. Krause, Kegl e Schick (2007) adaptaram o exame para averiguar a qualidade dos intérpretes educacionais que fazem uso do Cued Speech (CS), ou seja, da articulação oral 
associada a pistas visuais produzidas com a mão para que os sons (fonemas) das línguas faladas sejam percebidos perto da face. Após a validação do teste piloto, ele foi aplicado com 24 intérpretes e os resultados demonstram que esse instrumento é válido e confiável, comparável a outras versões do exame, contudo concluíram ser necessário repetir as aplicações para confirmar essa descoberta. Os resultados do teste também mostram a precariedade nos serviços de interpretação para alunos surdos e com deficiência auditiva, o que prejudica o acesso ao ambiente da sala de aula.

O estudo de Stewart e Kluwin traz uma revisão de literatura sobre interpretação educacional, em que foram comparadas as orientações apontadas na política educacional e o que acontece em sala de aula, de acordo com o que é relatado nas pesquisas analisadas. Os autores afirmam que faltam fundamentos teóricos sobre a atividade de interpretação educacional e que várias são expectativas quanto às responsabilidades dos profissionais. Stinson e Liu observaram processos de inclusão de alunos surdos, identificaram acomodações que professores regulares de sala de aula, professores de surdos e intérpretes podem fazer para promover a integração do aluno surdo. Afirmam que os intérpretes contribuem para a participação ativa do aluno, sumariam 16 estratégias específicas para superar as barreiras à participação dos alunos surdos.

Antia e Kreimeyer apresentam a conjuntura de sala de aulas inclusivas distinguindo a atuação de tradutores e intérpretes de língua de sinais (TILS) a depender do nível de ensino dos alunos surdos. Consideram que há, pelo menos, dois modelos de atuação: um em que os profissionais desenvolvem uma interpretação literal, sem envolvimento nos aspectos pedagógicos; outro em que eles esclarecem as orientações dos professores, facilitam a interação entre colegas, orientam as crianças surdas e mantêm os professores informados sobre o progresso das crianças surdas. Os professores preferem esse intérprete ativo e participante no processo de ensino-aprendizagem dos alunos.

Ainda abordando a interpretação em sala de aula, os estudos experimentais também se destacam. Napier fez um estudo descritivo 
a fim de identificar estratégias interpretativas durante uma palestra universitária e como os profissionais lidaram com influências sociolinguísticas do ambiente discursivo. Averiguou que os intérpretes usavam a interpretação livre ou literal, mas que intercalavam os estilos de interpretação. Seal aplicou uma série de testes para verificar as habilidades cognitivas dos intérpretes, buscando determinar o perfil de atributos cognitivos, motores, de atenção e de personalidade. Observou que o raciocínio abstrato dos profissionais apresenta um nível bastante alto e que os resultados dos exames são similares aos dos intérpretes que também atuam em contexto comunitário. Marschark et al. aplicaram testes de compreensão de situações interpretativas, com objetivo de levantar as preferências de comunicação dos alunos surdos e como essas configurações impactam no seu aprendizado. Os resultados demonstraram que a comunicação no modo eleito pelo aluno contribui para a motivação, participação e aprendizagem.

Napier e Barker tratam da educação universitária de surdos na Austrália e da interpretação em Auslan (Língua de Sinais Australiana). Em resposta às entrevistas, a maioria dos alunos surdos afirma preferir uma interpretação livre dos profissionais em comparação a uma interpretação de abordagem predominantemente literal. Alguns preferem os que combinam os dois tipos de interpretação, assim os estudantes podem acessar o conteúdo da palestra em Auslan enquanto acessam terminologia específica da disciplina ou a linguagem acadêmica em inglês. Igualmente, Marschark et al. tratam do acesso ao ensino superior por meio da interpretação de língua de sinais, da mesma forma que problematizam as preferências de interpretação dos alunos (interpretação versus transliteração). Os dados indicam que os alunos surdos adquirem menos conhecimento do que os ouvintes de aulas interpretadas em nível universitário. Paralela a essa pesquisa, Marschark et al. também tratam da compreensão e dos benefícios da interpretação simultânea de língua de sinais e do acesso ao texto em tempo real para a aprendizagem em sala de aula por alunos surdos. Não constataram diferença significativa na aprendizagem ao utilizar os dois recursos ao mesmo 
tempo. Por sua vez, Marschark et al. compararam a aprendizagem através de instrução direta (professor usando língua de sinais) e a aprendizagem mediada por intérpretes para alunos surdos universitários. Constatam que os dois tipos de aprendizagem foram igualmente eficazes para alunos surdos sob as diversas situações estudadas, mas ainda menor quando comparada com a aprendizagem dos alunos ouvintes universitários.

Moody aborda a dicotomia entre interpretação literal versus não literal e a concepção de fidelidade, considerando as especificidades da interpretação educativa. O autor conclui que uma interpretação fiel é idealmente uma interpretação que é coconstruída entre o orador e o intérprete. Wolbers, Dimling, Lawson e Golos estudaram a interpretação paralela e divergente do discurso original em uma sala de aula de escola primária com a atuação de uma intérprete altamente qualificada. Constataram que 33,2\% da interpretação paralela em contrapartida à interpretação divergente, em que o intérprete adicionou ou reduziu elementos de significado, ocorreu em $66,8 \%$ das vezes. Contudo, os acréscimos intencionais ao discurso foram desenvolvidos para alcançar uma maior compreensão pelo aluno surdo.

Fitzmaurice problematiza a atuação de intérpretes educacionais não credenciados, ou seja, sem certificação ou avaliação profissional, em escolas rurais. Os resultados indicam que esses intérpretes realizam quatro funções principais na escola: preparação do ambiente, da equipe e dos materiais; interpretar uma variedade de conteúdo; interagindo com os interlocutores; e instruindo diretamente os alunos. Meulder, Napier e Stone, ao analisarem a interpretação em dupla de uma defesa de doutorado de acadêmico surdo, descrevem as estratégias interpretativas em dupla levando em consideração a situação e os elementos verbais e não verbais, como também a articulação com o orador surdo.

\section{- Inclusão escolar:}

No que diz respeito aos trabalhos sobre inclusão escolar perfazem $18 \%$, ou seja, sete artigos. Stinson e Antia problematizam 
a abordagem inclusiva da educação dos alunos surdos, a fim de estabelecer um panorama da interpretação. Destacam que os intérpretes auxiliam o professor, especificamente com o aluno surdo, isso inclui ver as questões dos alunos ajudando-os com atividades e com a aprendizagem, conforme for necessário. Sobre o desenvolvimento dos alunos surdos, Luckner e Muir identificaram os fatores que contribuíam para o desempenho escolar dos alunos surdos. Os resultados demonstravam a importância da família, de uma didática visual e da consciência de alunos a respeito de sua condição.

Hyde, Ohna e Hjulstadt fazem uma análise comparativa dos sistemas de ensino para alunos surdos na Noruega e na Austrália, elucidando as diferenças nas aplicações da educação inclusiva inerentes às políticas dos dois países. Os pesquisadores indicam que há limitação no número de intérpretes de língua de sinais australiana (Auslan), mais presentes nas universidades, sendo necessário aumentar cada vez mais o número deles nas escolas de ensino médio. Os resultados do estudo australiano sugerem que a interpretação seria uma forma eficaz para muitos alunos surdos para complementar a comunicação em sala de aula.

Ayantoye e Luckner problematizaram a complexidade em ambientes inclusivos com alunos surdos pela diversidade cultural e/ ou linguística. Identificaram fatores que contribuem para o sucesso de alunos surdos, dentre eles está o serviço de interpretação educacional. Becker e Bowen, a partir da perspectiva dos prestadores de serviços para educação de alunos surdos e aprendizes de inglês, confirmam a diversidade do público com necessidades únicas de comunicação, acadêmicas e culturais, o que requer atenção à singularidade de cada aluno, individualmente também para o serviço de interpretação.

Torres estudou as perspectivas de estudantes universitários surdos/latinos, examinando as experiências da primeira geração nessa condição. Enquanto minoria linguística, há relatos de superação, apoiados pela força pessoal, autonomia e aproveitamento dos serviços de suporte, como a interpretação; e possuindo as características pessoais de assertividade e independência. Lang 
foca no ensino superior, relatando a escassez de pesquisas sobre educação de surdos nesse nível de ensino. O autor sintetiza pesquisas relevantes, elencando orientações para reter e melhorar o desempenho de acadêmicos surdos. Menciona que existem poucas pesquisas que orientem como ofertar serviços aos estudantes surdos, incluindo a interpretação e que as informações chegam ao aluno surdo por meio de interpretação, legendagem em tempo real, por meio de aulas particulares e anotações.

\section{- Formação do intérprete:}

Sintetizamos aqui os trabalhos sobre formação, com sete publicações ao total. Storey e Jamieson levantaram os recursos utilizados por intérpretes educacionais para aumentar seu vocabulário em sinais, sejam eles humanos ou tecnológicos. Constatou-se um número expressivo de profissionais que afirmaram reconhecer a necessidade de estudo contínuo para atualização do vocabulário. Fitzmaurice apresenta um estudo qualitativo que demonstra o engajamento dos intérpretes na aprendizagem de alunos surdos, especialmente no desenvolvimento da capacidade de raciocínio de ordem superior, comparado com professores das disciplinas. Roush realizou uma pesquisa-ação para examinar o design de protótipo de software utilizado para anotação de vídeo criado para analisar interpretações. As duas pesquisas de 2010 se referem ao profissional como "interpreter educators" (educadores intérpretes), o que denota o caráter de docência ao cargo.

No ano seguinte, Madden discorre sobre formação continuada para intérpretes fornecida pelo governo australiano para aprimorar as habilidades no uso de língua de sinais australiana (Auslan) e a aplicação da pedagogia bilíngue em sinais. Os participantes afirmaram que iniciativas como essa ampliam o entendimento do papel profissional na atividade interpretativa. Cox compartilha uma experiência de ensino de intérpretes aprendizes, explorando o YouTube como uma ferramenta eficaz em sua formação. A ferramenta colaborou no ensino, possibilitando o registro de anotações de fee- 
dback, além de fornecer apoio didático ao professor para demonstrar variadas situações interpretativas.

Bontempo e Hutchinson relatam um treinamento contínuo realizado com um grupo de intérpretes de uma escola secundária na Austrália, no qual foram relatadas práticas adotadas. Com base em autoavaliações, observações e discussões com os profissionais, os autores levantaram lacunas de habilidades e elaboraram um treinamento com base nas necessidades, com o propósito de orientá-los ao desenvolvimento profissional. Bentley-Sassaman, Houser, Morrison apresentam uma experiência de treinamento para intérpretes educacionais na Pensilvânia (Estados Unidos) para atender às necessidades de interpretação dos alunos surdos no estado. O curso se deu por meio do acompanhamento individualizado com mentores e foi estruturado por ciclos de aprendizagem com base em tarefas que, após serem realizadas pelos intérpretes, precisavam analisá-las, receber críticas do professor e dos colegas e aplicar esses comentários para melhorar os próximos trabalhos.

\section{- Educação de Surdos:}

No corpus há um trabalho que trata de forma central sobre Educação de surdos (3\%). Por ser um estudo pioneiro, Maxwell se vê em situação de uso do bimodalismo na educação de surdos, em meio ao início da implementação de uma abordagem de comunicação total. A autora cita o receio de pais e professores em usar sinais combinados à fala, o que reflete no trabalho dos intérpretes.

\section{- Políticas Educacionais:}

Quando da categoria de Políticas Educacionais, destacamos o trabalho (3\%) de Jokinen que, pautado nos princípios da "Convention on the Rights of Persons With Disabilities" (em português, Convenção das Nações Unidas sobre os Direitos das Pessoas com Deficiência), discute a educação de surdos e problematiza a inclusão escolar e os critérios para o acesso dessas pessoas a educação 
não-discriminatória, que seja equânime. Fundamentada nos direitos humanos dos estudantes surdos em contextos educacionais, o artigo apresenta justificativas que colocam a língua de sinais em evidência e que considera a condição dessa minoria apoiada nos direitos humanos das pessoas surdas, evidenciando a perspectiva dos direitos linguísticos e culturais. Traz dados contextualizados sobre a educação bilíngue e suscita a reflexão sobre a modelos educacionais em alguns países da Europa e apresenta uma proposta preliminar de avaliação da inclusão de surdos, que analisa fatores como o respeito a diversidade das identidades das crianças surdas e de sua cultura e que se entende ao examinar a legislação escolar, o currículo, os materiais de aprendizagem, a formação de professores, as disciplinas e as práticas escolares e apoio dado à família.

\section{- Competências interpretativas:}

Há um trabalho sobre competências interpretativas elaborado por Yarger. O autor desenvolveu um estudo de desempenho dos intérpretes com base no EIPA, com a participação de 63 intérpretes educacionais que trabalhavam em áreas rurais, nos níveis do ensino fundamental e médio. Analisou as experiências na preparação para as aulas e registrou as percepções deles e, na fase de aplicação do exame, apesar de ter sido feita com 43 deles, constatou que apenas 10 desses profissionais tinham formação para atuação na área, além de que nenhum dos profissionais possuía certificação RID (Registry of Interpreters for the Deaf) ou de qualquer outro órgão certificador. Os intérpretes relataram preocupações sobre sua compreensão limitada da Língua de Sinais Americana (American Sign Language - ASL) e na capacidade de interpretar da ASL para o inglês, além de opinar sobre salário, treinamento e status profissional.

\section{Segurança do trabalho:}

Não menos importante, encontramos um trabalho que trata da segurança do trabalho. Decaro, Feuerstein, Hurwitz estudaram os 
transtornos traumáticos cumulativos entre Intérpretes Educacionais como um risco ocupacional. Sugerem que menos pausas de descanso durante as sessões de interpretação e maior índice do ritmo dos movimentos dos dedos e mãos (estilos de interpretação) foram associadas ao aumento da dor e fadiga.

\section{Discussão}

Apreendendo o desenho dos trabalhos levantados, ao desenvolvermos uma revisão dos artigos, constatamos que tanto o tema de interação em sala de aula quanto o de inclusão escolar problematizam os papeis dos intérpretes, assim como as necessidades de projetos de educação inclusiva, e marcam a singularidade de cada escola e sujeitos envolvidos. Os trabalhos também apontam a transição das lutas iniciais da formação como um treinamento de preparação para provas de credenciamento ou de formação em serviço em secretarias de educação locais para formações continuadas e/ou em curso superior, com metodologias diferenciadas.

Os discursos apreendidos nessas pesquisas são enunciações concretas. Do mesmo modo, refratam discursos de contextos mais amplos de produção e circulação de luta política tanto da comunidade surda quanto dos intérpretes. Lutas também de profissionais que trabalham com línguas vocais-auditivas, já que "a formação dos futuros intérpretes (e tradutores) deveria ter lugar nas universidades, onde a combinação de ensino e pesquisa é um princípio fundamental" (Pöchhacker 3).

No Brasil, o campo de formação de tradutores e intérpretes tem seguido uma tendência de pesquisas chamadas de didática da tradução, procuram também "alinhar as atividades de ensino e avaliação aos objetivos de aprendizagem pretendidos, de tal forma que todos os elementos do processo de ensino-aprendizagem se concentrem na mesma competência a ser a ser adquirida [...]" (Nogueira, Vasconcelos e Santos 366). 
O ensino de intérpretes de língua de sinais baseado em pesquisas tem sido uma necessidade do campo (Roy), ou seja, docentes e pesquisadores podem tomar proveito de evidências disponíveis a partir de pesquisas sobre a formação de intérpretes. Há uma necessidade social de estudos que versem sobre didática da interpretação, uma pedagogia voltada para a língua em uso e face a face, para a atividade "de viabilizar a comunicação entre surdos e ouvintes, atuando na fronteira entre os sentidos da língua oral (português) e da língua de sinais em um processo ativo, dinâmico e dialético" (Kotaki e Lacerda 206).

\section{Considerações finais}

Constatamos que as contribuições desses estudos para compreender o fenômeno da interpretação em sala de aula na mediação pedagógica são significativas. Contudo, há inúmeras possibilidades de delimitação do objeto de pesquisa e de análise que ainda não foram contemplados. Esse levantamento é um passo para qualquer pesquisador que se interesse sobre a interpretação educacional, pois compilamos os trabalhos e temas de interesse, bem como a mudança ao longo do tempo para refletir como essas pesquisas se desenvolveram.

Notamos que não há regularidade na publicação de pesquisas que tratam sobre a interpretação educacional e identificamos lacunas temporais de estudos nas revistas analisadas. Na última década, por exemplo, as revistas SLS, JDSDE e SLTI não tiveram artigos publicados. Concluímos que alguns temas foram pouco abordados, como as questões que envolvem saúde ocupacional, competências para interpretar, aspectos linguísticos e culturais relacionados à interpretação, por exemplo.

Concebendo que fazer pesquisa consiste no ato de interpretar os fenômenos sociais, buscamos compreender o desenvolvimento de um subcampo dos Estudos da Tradução, ou seja, a Interpretação Educacional. Constatamos que os pesquisadores dialogam com 
seus sujeitos (objetos), abrangendo recursos metodológicos que essencialmente envolvem a linguagem, desde entrevista a gravações da língua em uso. Assim, os autores dialogam nos textos com outros autores/outras pesquisas e, dessa forma, produzem conhecimento, avançam com estudos em interpretação educacional. Concluímos que as pesquisas são essencialmente dialógicas, tanto em seus princípios teóricos, metodológicos, quanto analíticos.

\section{Referências}

Albres, Neiva de Aquino. Afetividade e subjetividade na interpretação educacional. Rio de Janeiro: Ayvu, 2019.

Albres, Neiva de Aquino. As políticas de contratação dos intérpretes educacionais. Conferência online com o grupo de pesquisa InterTrads, 30 de setembro de 2019. Florianópolis: UFSC, 2019.

Albres, Neiva de Aquino. "As novas tendências metodológicas nos estudos da tradução/interpretação entre o par Português/Libras”. Estudos da língua brasileira de sinais III, editado por Ronice Müller de Quadros e Markus J. Weininger. v. 3. Florianópolis: Editora Insular, 2014, pp. 13-34. 20/02/2020. Disponível em: $<$ https://repositorio.ufsc.br/handle/123456789/178906>.

Albres, Neiva de Aquino. "Estudos sobre os papéis dos intérpretes educacionais: uma abordagem internacional”. Revista Fórum. 34 (2016): 48-62. 10/09/2018. Disponível em: < http://www.ines.gov.br/seer/index.php/forum-bilingue/article/ view/99/ $91>$.

Albres, Neiva de Aquino. Intérprete educacional: políticas e práticas em sala de aula inclusiva. São Paulo: Harmonia, 2015.

Cad. Trad., Florianópolis, v. 41, $\mathrm{n}^{0}$ esp. 2, p. 68-106, ago/dez, 2021.96 
Albres, Neiva de Aquino; Costa, Mairla Pereira Pires. "O intérprete educacional em dissertações e teses sobre educação de surdos: focalizando temas de interesse (1999 a 2018)". Colóquio internacional de educação especial e inclusão escolar, 2019, Florianópolis. Anais eletrônicos [...] Campinas, GALOÁ, 2019. 09/11/2019. Disponível em: < https://proceedings.science/proceedings/100081/ authors $/ 354040>$.

Albres, Neiva de Aquino; Rodrigues, Carlos Henrique. "As funções do intérprete educacional: entre práticas sociais e políticas educacionais". Bakhtiniana. 13.3 (2018): 16-41. 02/06/2020. Disponível em: < http://revistas.pucsp.br/index.php/ bakhtiniana/article/view/35335/26540>.

Albres, Neiva Aquino; Lacerda, Cristina Broglia F. de. "Interpretação educacional como campo de pesquisa: estudo bibliométrico de publicações internacionais e suas marcas no campo nacional". Cadernos de Tradução. 1.31 (2013): 179-204. 07/05/2020. Disponível em: <https://periodicos.ufsc.br/index.php/traducao/ article/view/2175-7968.2013v1n31p179>.

Alves, Daniel Antonio de Sousa; Vasconcellos, Maria Lucia Barbosa. "Metodologias de pesquisa em Estudos da Tradução: uma análise bibliométrica de teses e dissertações produzidas no Brasil entre 2006-2010". DELTA. 32.2 (2016): 375-404. 07/05/2020. Disponível em: < https://www.scielo.br/pdf/ delta/v32n2/1678-460X-delta-32-02-00375.pdf $>$.

Baktin, Mikhail. Notas sobre literatura, cultura e ciências humanas. Tradução de Paulo Bezerra. São Paulo: Editora 34, 2017.

Bakhtin, Mikhail. Para uma filosofia do ato responsável. Tradução de Valdemir Miotello e Carlos Faraco. São Carlos: Pedro \& João Editores, 2010.

Brait, Beth. "Análise e Teoria do Discurso". Bakhtin: outros conceitos-chave, editado por Beth Brait, São Paulo: Contexto, 2006, pp. 9-31.

Beuren, Ilse Maria e Souza, José Carlos de. "Em busca de um delineamento de proposta para classificação dos periódicos internacionais de contabilidade para o Qualis CAPES”. Rev. contab. Finanç. 19.46 (2008): 44-58. 20/06/2020. Disponível em: < https://www.scielo.br/j/rcf/a/sPp5PpvkPsCdY9vBJHRB6ZF/>. 
Borges, Cláudia de Oliveira. A importância dos periódicos de acesso aberto para o desenvolvimento da ciência e tecnologia do país. 2010. $103 \mathrm{f}$. Trabalho de Conclusão de Curso (Graduação em Biblioteconomia) - Universidade Federal do Estado do Rio de Janeiro (UNIRIO), Rio de Janeiro, 2010. 10/06/2020. Disponível em: < http://eprints.rclis.org/14653/1/CLAUDIA_DE_OLIVEIRA_ BORGES-E-LIS.pdf $>$.

Gessner, Aline Vanessa Poltronieri. "Intérprete educacional de língua de sinais para surdos: publicações internacionais em foco - 2010 a 2015.". Libras e sua tradução em pesquisa: interfaces, reflexões e metodologias, organizado Neiva de Aquino Albres, Florianópolis: Biblioteca Universitária UFSC, 2017. 20/02/2020. Disponível em: < http://libras.ufsc.br/wp-content/uploads/2017/03/ALBRES2017-Ebook_Libras-e-sua-tradu \%C3\% A7\%C3\% A3o-em-pesquisa.pdf > .

Jordan, I. King.; Gustason, Gerilee.; Rosen, Roslyn. "An update on communication trends at programs for the deaf". American Annals of the Deaf. 124.3 (1979): 350-357.

Marschark, M.; Sapere, P.; Seewagen, R. Preface. Sign language interpreting and interpreter education: Direction for research and practice, editado por Marc Marschark, Rico Peterson, and Elizabeth A. Winston, New York: Oxford University Press. 2005, pp. v-X.

Metzger, Melanie. Os destaques das pesquisas sobre interpretação de língua de sinais no contexto acadêmico da interpretação comunitária. Cadernos de Tradução. 2.26 (2010):13-61. Portal de Periódicos da UFSC. 10/05/2019. Disponível em: <https://periodicos.ufsc.br/index.php/traducao/article/ view/2175-7968.2010v2n26p13 > .

Napier, Jemina. "University interpreting: linguistic issues for consideration". Journal of Deaf Studies and Deaf Education. 7.4 (2002): 281-301.

Nogueira, Tiago; Vasconcellos, Maria Lúcia; Santos, Silvana. "Formação de intérpretes de Português-Libras: proposta de unidades didáticas construídas em torno de tarefas de interpretação". Formação de tradutores: por uma pedagogia e didática da tradução no Brasil, editado por Germana Henriques Pereira e Patrícia Rodrigues Costa, Campinas, SP: Pontes Editores, 2008, pp. 361-392.

Pöchhacker, Franz. "The Role of Research in Interpreter Education”. Translation 
\& Interpreting. 2.1 (2010): pp. 1-24. Tradução de Mylene Queiroz. 19/06/2020. Disponível em: < http://www.interpret2b.com/cms/uploads/publicacoes/ publicacao_8/o\%20papel $\% 20$ da $\% 20$ pesquisa $\% 20$ na $\% 20$ formacao $\% 20 \mathrm{de} \% 20$ interpretes $\overline{\%} 20$ - $\% 20$ Franz $\% 20$ Pochhacker.pdf $>$.

Pym, Anthony et al. "Exploring Translations Theories". Cadernos de Tradução. 36.3 (2016): 214-317. Portal de Periódicos da UFSC. 19/06/2020. Disponível em: $<$ https://periodicos.ufsc.br/index.php/traducao/article/view/2175-7968.2016v36 n3p214>.

Rodrigues, Carlos Henrique. A busca por semelhança interpretativa no processo de interpretação simultânea para a língua de sinais. Estudos da língua brasileira de sinais III, editado por Ronice Müller de Quadros e Markus J. Weininger, v. 3. Florianópolis: Editora Insular: Florianópolis: PGET/UFSC, 2014, pp. 35-70. 20/02/2020. Disponível em: < https://repositorio.ufsc.br/ handle/123456789/178906>.

Rodrigues, Carlos Henrique; Santos, Silvana Aguiar dos. "A interpretação e a tradução de/para línguas de sinais: contextos de serviços públicos e suas demandas”. Tradução em Revista. 24 (2018): 1-29. 15/02/2020. Disponível em: $<$ https://www.maxwell.vrac.puc-rio.br/34535/34535.PDF > .

Roy, Cynthia B. Training interpreters: past, present and future. Innovative practices for teaching sign language interpreters, editado por Cynthia B. Roy, Washington, DC: Gallaudet University Press, 2000, p.1-14.

Santiago, Vânia de Aquino. "O uso da anotação da língua de sinais na apresentação de publicações acadêmicas: analisando as escolhas que favorecem o entendimento do leitor". IV Congresso Brasileiro de Pesquisas em Tradução e Interpretação de Língua Brasileira de Sinais e Língua Portuguesa, Florianópolis, 12 a 14 de novembro de 2014. Anais [...]. Florianópolis, Universidade Federal de Santa Catarina, 2014. 20/03/2020. Disponível em: < http://www.congressotils.com.br/ anais/2014/2966.pdf $>$.

Sobral, Adail Ubirajara. "Elementos para uma definição do estético segundo o Círculo de Bakhtin". IX Semana de Letras da UFOP, 2006. Anais [...]. Ouro Preto: Editora Aldrava Letras e Artes, 2006, pp. 11-21. 
Schaff, Adam. A relação cognitiva, o processo do conhecimento, a verdade. História e verdade, editado por Adam Schaff, Tradução de Maria Paula Duarte, São Paulo: Editora Martins Fontes, 1995, p. 65-95.

Vanti, Nadia Aurora Peres. "Da bibliometria à webometria: uma exploração conceitual dos mecanismos utilizados para medir o registro da informação e a difusão do conhecimento". Ciência da Informação. 31.2 (2002): 369-379. 20/06/2020. Disponível em: <https://www.scielo.br/j/ci/a/ SLKfBsNL3XHPPqNn3jmqF3q > .

Vasconcellos, Maria Lúcia. "Tradução e Interpretação de Língua de Sinais (TILS) na Pós-Graduação: a afiliação ao campo disciplinar Estudos da Tradução". Cadernos de Tradução. 2. 26 (2010): 119-143. Portal de Periódicos da UFSC. 19/06/2020. Disponível em: <https://periodicos.ufsc.br/index.php/traducao/ article/view/2175-7968.2010v2n26p119/14226>.

Zawolkow, Esther G.; DeFiore, Sadie. "Educational interpreting for elementary and secondary level hearing-impaired students". American Annals of the Deaf. 131.1 (1986): 26-28. 20/06/2020. Disponível em: <https://muse.jhu.edu/ article $/ 385839 / \mathrm{pdf}>$.

Neiva de Aquino Albres. E-mail: neiva.albres@ufsc.br. https://orcid.org/00000003-1567-297X.

Mairla Pereira Pires Costa. E-mail: mairla.libras@gmail.com. https://orcid. org/0000-0001-5285-5850. 


\section{APÊNDICE}

\begin{tabular}{|c|c|}
\hline Revistas & Referências \\
\hline $\begin{array}{c}1 \\
\text { American Annals } \\
\text { of the Deaf } \\
(14 \\
\text { Artigos) }\end{array}$ & $\begin{array}{l}\text { MAXWELL, M. M. Simultaneous communication: the } \\
\text { state of the art and proposal for change Sign Language } \\
\text { Studies, v. 69, p. 333-390, 1990. https://muse.jhu.edu/ } \\
\text { article/507082/pdf. } \\
\text { DECARO, J. J., FEUERSTEIN, M., \& HURWITZ, T. } \\
\text { A. Cumulative Trauma Disorders Among Educational } \\
\text { Interpreters. American Annals of the Deaf, v. 137, n. 3, } \\
\text { p. 288-292, 1992. } \\
\text { https://muse.jhu.edu/article/385107/pdf. } \\
\text { BEAVER, D. L.; HAYES P. L.; LUETKE-STAHLMAN, } \\
\text { B. In-service trends: general education teachers working } \\
\text { with educational interpreters. American Annals of the } \\
\text { deaf, v. 140, n. 1, p. 38-46, 1995. Disponivel em: https:// } \\
\text { muse.jhu.edu/article/384792/pdf. } \\
\text { SHAW, J.; JAMIESON, J. Patterns of classroom discourse } \\
\text { in integrated, interpreted elementary school setting. } \\
\text { American Annals of the Deaf, v. 142, n. 1, p. 40-47, } \\
\text { 1997. https://muse.jhu.edu/article/384649/pdf. } \\
\text { ANTIA, Shirin. D.; KREIMEYER, K. H. The Role of } \\
\text { Interpreters in Inclusive Classrooms. American Annals of } \\
\text { the Deaf, v. 146, n. 4, p. 355-365, 2001. https://muse. } \\
\text { jhu.edu/article/384118/pdf. } \\
\text { LUCKNER, J. L.; MUIR, S. Successful students who are } \\
\text { deaf in general educational settings. American Annals of } \\
\text { the Deaf, v. 146, n. 5, p. 435-445, 2001. https://muse. } \\
\text { jhu.edu/article/384423/pdf. } \\
\text { YARGER, C. C. Educational Interpreting: Understanding } \\
\text { the Rural Experience. American Annals of the Deaf, } \\
\text { v. 146, n. 1, p. 16-30, 2001. https://muse.jhu.edu/ } \\
\text { article/383818/pdf. }\end{array}$ \\
\hline
\end{tabular}

Cad. Trad., Florianópolis, v. 41, $\mathbf{n}^{0}$ esp. 2, p. 68-106, ago/dez, 2021.101 
HYDE, M., OHNA, S. E.; HJULSTADT, O. Education of the Deaf in Australia and Norway: A Comparative Study of the Interpretations and Applications of Inclusion. American Annals of the Deaf, v. 150, n. 5, p. 415-426, 2005. https://muse.jhu.edu/article/195088/pdf.

WOLBERS, Kimberly A.; DIMLING, Lisa M.; LAWSON, Heather R.; \& GOLOS, Debbie B. Parallel and Divergent Interpreting in an Elementary School Classroom. American Annals of the Deaf, v. 157, n. 1, p. 48- 65 , 2012. https://muse.jhu.edu/article/473958/pdf.

AYANTOYE, Catherine Adekemi; LUCKNER, John L. Successful students who are deaf or hard of hearing and culturally and/or linguistically diverse in inclusive settings. American Annals of the Deaf, v. 160, n. 5, p. 453-466, 2015. https://muse.jhu.edu/article/608792.pdf.

FITZMAURICE, S. Unregulated autonomy: Uncredentialed educational interpreters in rural schools. American Annals of the Deaf, v. 162, n. 3, p. 253-264, 2017. https://muse.jhu.edu/article/667535/pdf.

JOKINEN, Markus. Inclusive education - a sustainable approach? American Annals of the Deaf, v. 163 n. 1, p. 70-77, 2018. https://muse.jhu.edu/article/691969/pdf.

BECKER, Sharon J., BOWEN, Sandy K. Service providers perspective on the education of students who are deaf or hard of hearing and english learners. American Annals of the Deaf, n. 3, p. 356-373, 2018. https://muse. jhu.edu/article/700918/pdf.

TORRES, Franklin C. Facing and Overcoming Academic Challenges: Perspectives From Deaf Latino/a FirstGeneration College Students. American Annals of the Deaf, v. 164, n. 1, p. 10-36, 2019. https://muse.jhu.edu/ article/723665/pdf. 


\begin{tabular}{|c|c|}
\hline $\begin{array}{c}2 \\
\text { Sign Language } \\
\text { Studies } \\
(2 \text { artigos })\end{array}$ & $\begin{array}{l}\text { JOHNSON, Kristen. Miscommunication in interpreted } \\
\text { classroom interaction. Sign Language Studies, v. 70, p, } \\
\text { 1-34, 1991. https://muse.jhu.edu/article/507072/pdf. } \\
\text { MARSCHARK, Marc; SAPERE; Patricia; } \\
\text { CONVERTINO, Carol; SEEWAGEN, Rosemarie, and } \\
\text { MALTZEN, Heather. Comprehension of Sign Language } \\
\text { Interpreting: Deciphering a Complex Task Situation. Sign } \\
\text { Language Studies v. 4, n. 4, p. 345-368, 2004. https:// } \\
\text { muse.jhu.edu/article/170845/pdf. }\end{array}$ \\
\hline $\begin{array}{c}3 \\
\text { Journal of Deaf } \\
\text { Studies and Deaf } \\
\text { Education } \\
(14 \\
\text { artigos) }\end{array}$ & $\begin{array}{l}\text { STEWART, David A.; KLUWIN, Thomas N. The } \\
\text { Gap Between Guidelines, Practice, and Knowledge in } \\
\text { Interpreting Services for Deaf Students. The Journal } \\
\text { of Deaf Studies and Deaf Education, v. 1, n. 1, } \\
\text { p. 29-39, 1996. https://academic.oup.com/jdsde/ } \\
\text { article/1/1/29/356256. } \\
\text { SCHICK, Brenda; WILLIANS, Kevin, BOLSTER, } \\
\text { Laurie. Skill lives of educational interpreters Working } \\
\text { in Public Schools. The Journal of Deaf Studies and } \\
\text { Deaf Education, v. 4, n. 2, p. 144-155, 1999. https:// } \\
\text { academic.oup.com/jdsde/article/4/2/144/455686. } \\
\text { STINSON, M; ANTIA, Shirin. Considerations in } \\
\text { educating deaf and hard-of-hearing students in inclusive } \\
\text { settings. Journal of Deaf Studies and Deaf Education, } \\
\text { v. 4, n. 3, p. 163-175, 1999. https://academic.oup.com/ } \\
\text { jdsde/article/4/3/163/440893. } \\
\text { STINSON, M; LIU, Y. Participation of deaf and hard- } \\
\text { of-hearing students in classes with hearing students. } \\
\text { Journal of Deaf Studies and Deaf Education, v. } 4 \text {, n. } \\
\text { 3, p. 191-202, 1999. https://academic.oup.com/jdsde/ } \\
\text { article/4/3/191/440895. } \\
\text { LANG, Harry G. Higher Education for Deaf Students: } \\
\text { Research Priorities in the New Millennium. Journal } \\
\text { of Deaf Studies and Deaf Education, v. 7, n. 4, } \\
\text { p. 267-280, 2002. https://academic.oup.com/jdsde/ } \\
\text { article/7/4/267/399833 }\end{array}$ \\
\hline
\end{tabular}

Cad. Trad., Florianópolis, v. 41, n $^{0}$ esp. 2, p. 68-106, ago/dez, 2021.103 


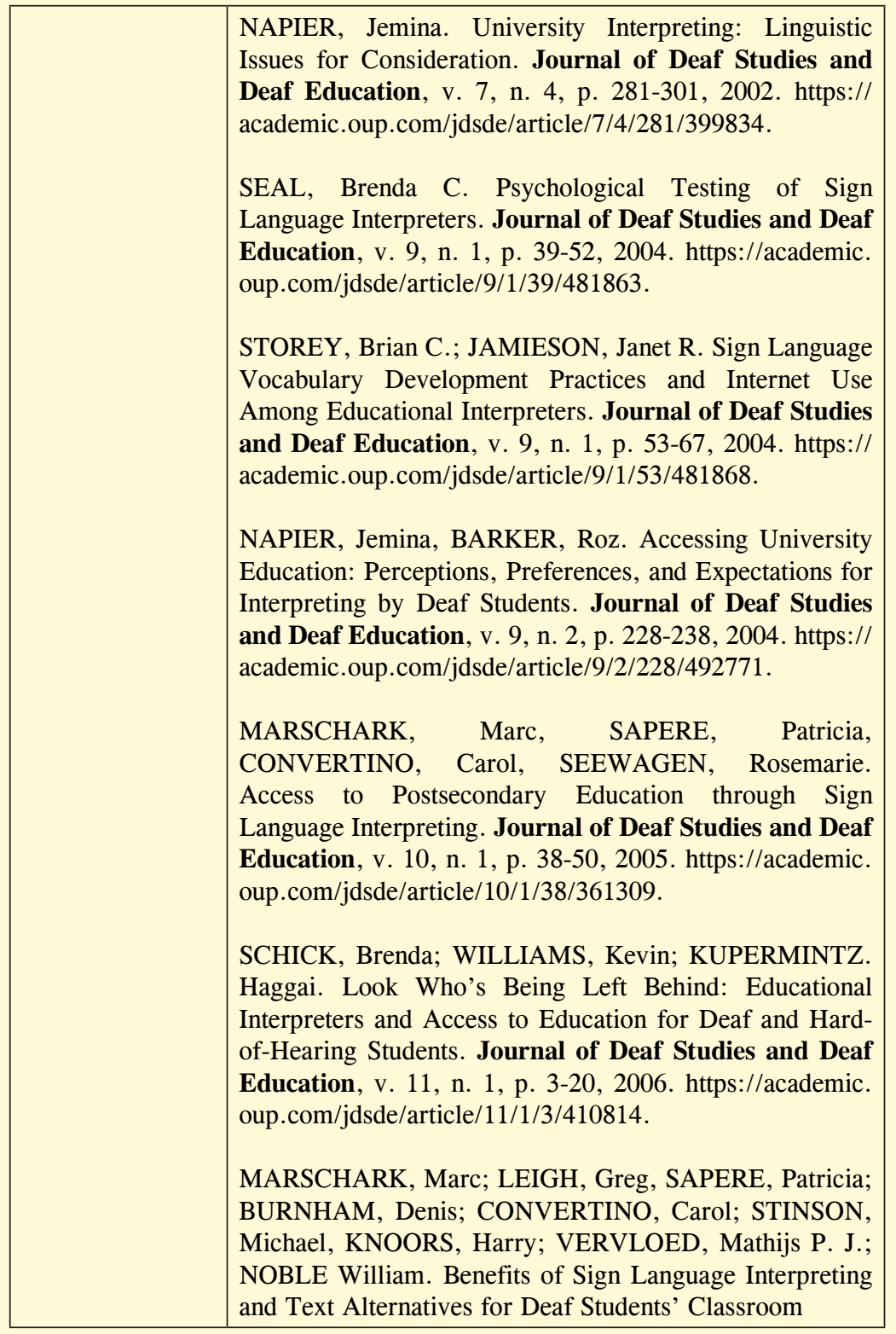

Cad. Trad., Florianópolis, v. 41, $n^{0}$ esp. 2, p. 68-106, ago/dez, 2021. 104 


\begin{tabular}{|c|c|}
\hline & $\begin{array}{l}\text { Learning. Journal of Deaf Studies and Deaf Education, } \\
\text { v. 11, n. 4, p. 421-437, 2006. https://academic.oup.com/ } \\
\text { jdsde/article/11/4/421/411839. } \\
\text { KRAUSE, Jean C., KEGL, Judy A.; SCHICK, Brenda. } \\
\text { Toward Extending the Educational Interpreter Performance } \\
\text { Assessment to Cued Speech. Journal of Deaf Studies } \\
\text { and Deaf Education, v. 13, n. 3, 432-450, 2007. https:// } \\
\text { academic.oup.com/jdsde/article/13/3/432/374308. } \\
\text { MARC, Marschark; SAPERE, Patricia; CONVERTINO, } \\
\text { Carol; PELZ, Jeff. Learning via Direct and Mediated } \\
\text { Instruction by Deaf Students. Journal of Deaf Studies and } \\
\text { Deaf Education, v. 13, n. 4, p. 546-561, 2008. https:// } \\
\text { academic.oup.com/jdsde/article/13/4/546/498613. }\end{array}$ \\
\hline $\begin{array}{c}4 \\
\text { The Sign } \\
\text { language } \\
\text { translator and } \\
\text { interpreter } \\
\text { (1 artigo) }\end{array}$ & $\begin{array}{l}\text { MOODY, Bill. Literal vs. Liberal: What Is a Faithful } \\
\text { Interpretation?. The Sign Language Translator and } \\
\text { Interpreter (SLTI), v. 1, n. 2, p. 179-220, } 2007 .\end{array}$ \\
\hline $\begin{array}{c}5 \\
\text { International } \\
\text { Journal of } \\
\text { Interpreter } \\
\text { Education } \\
\text { (7 artigos) }\end{array}$ & $\begin{array}{l}\text { FITZMAURICE, Steve. Teaching Goals of Interpreter } \\
\text { Educators. International Journal of Interpreter } \\
\text { Education, v. 2, p. 14-26, nov. 2010. https://www.cit- } \\
\text { asl.org/new/wp-content/uploads/2014/07/IJIE-vol2-14- } \\
\text { 24-fitzmaurice.pdf. } \\
\text { MADDEN, Maree. A Professional Development Initiative } \\
\text { for Educational Interpreters in Queensland. International } \\
\text { Journal of Interpreter Education, v. 3, nov. 2011. } \\
\text { https://www.cit-asl.org/new/a-professional-development- } \\
\text { initiative-for-educational-interpreters-in-queensland/. } \\
\text { ROUSH, Daniel R. Universal Design in Technology } \\
\text { Used in Interpreter Education. International Journal of } \\
\text { Interpreter Education, v. 2, nov. 2010. https://www. } \\
\text { cit-asl.org/new/universal-design-in-technology-used-in- } \\
\text { interpreter-education/. }\end{array}$ \\
\hline
\end{tabular}

Cad. Trad., Florianópolis, v. 41, n $^{0}$ esp. 2, p. 68-106, ago/dez, 2021.105 


\begin{tabular}{|l|l|}
\hline COX, Tom R. Broadcast Yourself: Youtube as a Tool \\
for Interpreter Education. International Journal of \\
Interpreter Education, v. 4, n. 1, maio, 2012. http:// \\
www.cit-asl.org/new/wp-content/uploads/2012/05/IJIE-4- \\
1-Broadcast-Yourself.pdf. \\
BENTLEY-SASSAMAN, Jessica; HOUSER, Sue \\
Ann; MORRISON, Brian. Interpreter Boot Camp: \\
Working Toward Achieving Interpreter Standards. \\
International Journal of Interpreter Education, v. 6, \\
n. 1 maio, 2014. http://www.cit-asl.org/new/wp-content/ \\
uploads/2014/06/5-Bentley-Sassaman-pp.42-54_final.pdf. \\
BONTEMPO, Karen; HUTCHINSON, Bethel. Striving \\
For an "A" Grade: A Case Study of Performance \\
Management of Interpreters. International Journal of \\
Interpreter Education, v. 3, nov. 2014. http://www. \\
cit-asl.org/new/wp-content/uploads/2014/07/5-Bontempo. \\
pdf. \\
MEULDER, Maartje De; NAPIER, Jemina. STONE, \\
Christopher. Designated or preferred? A deaf academic \\
and two signed language interpreters working together for a \\
PhD defence: A case study of best Practice. International \\
Journal of Interpreter Education, v. 10, n. 2, 5-26, dez. \\
2018. https://www.cit-asl.org/new/ijie-10-2-designated- \\
or-preferred/. \\
\hline
\end{tabular}

Fonte: As autoras.

Cad. Trad., Florianópolis, v. 41, n $^{0}$ esp. 2, p. 68-106, ago/dez, 2021.106 